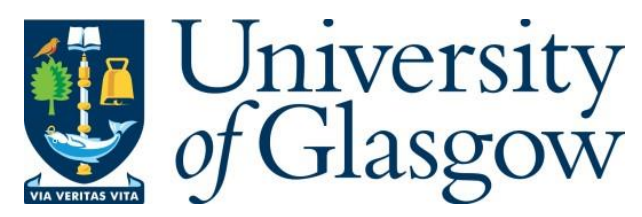

Rhew, N. D., Jones, D. R., Sama, L. M., Robinson, S., Friedman, V. J. and Egan, M. (2020) Shedding light on restorative spaces and faculty well-being. Journal of Management Education, (doi: 10.1177/1052562920953456).

There may be differences between this version and the published version. You are advised to consult the publisher's version if you wish to cite from it.

http://eprints.gla.ac.uk/222302/

Deposited on: 18 August 2020

Enlighten - Research publications by members of the University of Glasgow http://eprints.gla.ac.uk 
Shedding Light on Restorative Spaces and Faculty Well-Being

NICHOLAS D. RHEW - Corresponding Author

E. Craig Wall, Sr. College of Business Administration

Coastal Carolina University

PO Box 261954

Conway, SC 29528

Office Phone: +1 8433494175

nrhew@ coastal.edu

DAVID R. JONES

Newcastle Business School

University of Northumbria

david9.jones@northumbria.ac.uk

LINDA M. SAMA

The Peter J. Tobin College of Business

St. John's University

samal@stjohns.edu

SARAH ROBINSON

Adam Smith Business School

University of Glasgow

$\underline{\text { Sarah.Robinson.2@glasgow.ac.uk }}$

VICTOR J. FRIEDMAN

Masters Program in Organisational Development and Consulting

Action Research Center for Social Justice

Max Stern Yezreel Valley College

victorf@yvc.ac.il

MARK EGAN

The York Management School

University of York

mark.egan@york.ac.uk 


\begin{abstract}
The nature of academic work has changed dramatically in recent decades, resulting in part in decreased well-being among faculty. In this essay, we discuss these changes and their effects, with a focus on coping through restorative spaces. While faculty members may frequently conceal their restorative spaces in fear of how our time spent in them may be criticized, we seek to shed light on this important coping tool through sharing six unique restorative space narratives. Drawing from these vignettes, we encourage faculty members to share their own stories of restoration in their academic communities to counter the busyness narrative that pervades many academic spaces, and we call on colleges and universities to acknowledge and support the creation of restorative spaces for academics within their institutions.
\end{abstract}




\section{Shedding Light on Restorative Spaces and Faculty Well-Being}

Recent work has highlighted disturbing trends in students' mental health and well-being (Gaultney, 2010; Matthews, 2017; Stixrud, 2012). Notably, Stixrud (2012: 135) suggests that the "stress-soaked atmosphere" facing students "is poisonous to learning, judgment, and adaptive functioning - and to the physical and mental health of individuals and organizations." This stress and its results are particularly problematic for creativity and adaptability, which are two skills demanded by employers (Carnevale, Gainer, \& Meltzer, 1990; Chanler, 2019; Lippman et al., 2008). In response, offices devoted to student counseling and healthy living have proliferated on university campuses. But a focus on faculty mental health and well-being has been lagging at best, leading Smith and Ulus (2019) to ask, "Who cares for academics?"

The nature of academic work may be inherently problematic for well-being, and recent changes in higher education exacerbate this problem. Some have characterized the academic profession as a "calling" (Brower, 2013) or even "sacred" (Walsh, 2013). While a calling may sound pleasant, Bunderson and Thompson (2009) noted that those engaging in such deeply meaningful work were more likely to sacrifice pay, personal time, and comfort for work. Other scholars have highlighted the negative impacts on mental health of the peer review process and the regular rejection that characterizes its intensely competitive nature (Day, 2011; Horn, 2013). Lastly, shifts toward managerialism and an audit culture in recent decades exacerbate these problems (Bristow, Robinson, \& Ratle, 2019; Harley, Muller-Camen, \& Colling, 2004; Kenny, 2018) and may be counterproductive to quality work (Craig, Amernic, \& Tourish, 2014; Walsh, 2011). As public funding is cut and the pressure of rankings and assessment is increased, faculty are asked to do more and more with less and less (Baker, Pifer, \& Lunsford, 2016; Bristow, Robinson, \& Ratle, 2019; Flaherty, 2018; Shaw, 2014). 
In this essay, we explore how these trends and characteristics of academic work lead to resource depletion resulting in poor mental health and well-being, drawing on three theoretical perspectives: conservation of resources theory, the effort-recovery model, and attention restoration theory. We then shift our focus to improving faculty mental health and well-being through restorative spaces. Grounded in the literatures on respite, recovery, and restorative spaces, we provide six narratives to shed light on how faculty may use different, individually tailored restorative spaces to counter these pressures. By sharing these narratives and the themes found across them, we hope to encourage others in the academy to reflect on how they can or do use spaces for replenishment and restoration, rather than continued and quickened depletion and degeneration.

\section{A Problematic and Changing Landscape}

Recent work has pointed to increased workload as problematic for mental health and well-being (Baker, Pifer, \& Lunsford, 2016; Flaherty, 2018; Krause, 2018; Shaw, 2014; Smith \& Ulus, 2019). Shaw (2014: para. 5) reported, "Over half of academics, from the UK and overseas, say a heavy workload is having an impact on their mental health. A lack of support is also a key issue affecting $44 \%$ of respondents, which is felt across all ages from $25-64$ years. Just under half of respondents say they feel isolated, and others raise concerns around a 'bullying culture', job insecurity and a culture of long work hours." These results are supported by Baker, Pifer, and Lunsford (2016), who found that faculty across ranks in liberal arts colleges ranked workload as the greatest professional challenge they currently faced. Likewise, Flaherty (2018) reported that a majority of associate professors in liberal arts colleges surveyed by the Collaborative on Academic Careers in Higher Education noted difficulty in balancing teaching, research, and services activities, much less work and non-work commitments. In the context of Czech 
universities, Mudrak et al. (2018) found that work-family conflict was the most significant stressor for academics, which may be driven in part by expanding workloads.

What is behind these increased workloads? Many have decried the rise of managerialism and an audit culture within the academy and reductions in public funding of higher education (Bristow, Robinson, \& Ratle, 2019; Craig, Amernic, \& Tourish, 2014; Harley, Muller-Camen, \& Colling, 2004; Kenney, 2018; Walsh, 2011). Faculty workloads typically comprise teaching, research, and service activities, and each area has fallen prey to these pressures, leading KovoorMisra (2012: 279) to characterize the modern business school professor as an academic “'decathlete' who needs to excel in multiple 'sports' to be successful.” Interestingly, while educators are called upon to engage in deep reflection and thoughtful discourse, an emphasis on speed dictates how professors deliver their courses, grade student work, and respond to the research enterprise, driving a focus on efficiency over effectiveness. While some professions embrace slowness, academe has fostered an environment of haste and hurry (Berg \& Seeber, 2016).

In the context of teaching, managerialism and reductions in funding have led to increased reliance on non-tenure track appointments that typically carry a heavier teaching load, but come with little to no job security. Moreover, reductions in funding have led schools to seek more international students to fill funding gaps (Kraimer et al., 2019), which requires additional preparation time to find meaningful activities and examples for more diverse audiences (Mitchell, 2007). The demands of globalization have led to a proliferation of programs taught in English in locations where English is not the primary language. Bristow, Robinson, and Ratle (2019) demonstrate how this may be problematic through the story of one early career academic who added English training to his schedule to prepare to teach in English, incurring monetary 
and time costs. Lastly, reductions in funding have also led many schools to increase revenues through executive education and certificate programs, which requires teachers to augment their skills and knowledge to effectively reach a different audience (Harley, 2019; Mitchell, 2007).

Similar time pressures exist in the research and service components of faculty work. While the activities needed to do good research frequently require blocks of uninterrupted time (Mitchell, 2007), that time is easily pushed aside to accomplish more immediately pressing teaching and service tasks (Bristow, Robinson, \& Ratle, 2019). This is especially problematic in national contexts where research output is regularly evaluated nationally, with results informing resource allocation (Bristow, Robinson, \& Ratle, 2019). In these contexts, faculty face increased pressures to publish at the highest levels, which, given high rejection rates (Day, 2011), requires intense time commitment (Harley, 2019). In the service component, the increased reliance on non-tenure track faculty increases the traditional service load for those in tenure-track positions, as many contract faculty are not required to engage in service. Moreover, reductions in public funding have increased reliance on student-generated fees, which, in turn, has increased pressures to capture and retain more students and grant funding, tasks that are increasingly falling on early career academics (Bristow, Robinson, \& Ratle, 2019).

Lastly, apart from specific teaching, research, and service demands, or perhaps informing them, the characterization of the academic profession as a calling (Brower, 2013; Walsh, 2011) or as sacred (Walsh, 2011) likely leads to work overload. In his presidential address at the 2010 meeting of the Academy of Management, Walsh (2011: 223) stated, "Many of us are drawn to our work - maybe better said as drawn to our calling - by the allure of the life of the mind and for the chance to serve others," which are sentiments echoed by Brower (2013). While viewing work as a personal calling has been associated with many positive outcomes, Bunderson and 
Thompson (2009) noted that it also comes with costs, as a sense of calling leads to moral duty that, in turn, leads to increased sacrifice and exposure to exploitation. Thus, while seemingly harmless, perceptions of academic work as a calling-and the narratives built around them-may, in fact, lead faculty to take on more work, even especially challenging or emotionally taxing work, in an effort to fulfill their felt moral duty.

\section{Resources, Recovery, and Restoration}

Conservation of Resources (COR) theory (Hobfoll, 1989), the Effort-Recovery (ER) model (Meijman \& Mulder, 1998), and Attention Restoration Theory (ART)(Kaplan \& Kaplan, 1989) provide fruitful avenues for exploring why academic work and its changing nature are contributing to decreased faculty well-being and, more importantly, how to counter these effects. Born in the psychology literature as a model of stress, COR theory is a broadly applied motivation theory that suggests that individuals are motivated to protect and acquire resources, broadly defined and including psychological resources, and that resource loss leads to stress and burnout (Halbesleben et al., 2014; Hobfoll, 1989). The ER model posits that effort - including psychological effort - is limited and that expending that limited effort in work tasks leads to psychological and physiological reactions, including mental fatigue (Flaxman et al., 2012; Meijman \& Mulder, 1998). According to both COR theory and the ER model, a failure to adequately address psychological resource depletion can lead to a negative spiral, making resource acquisition and recovery more difficult and decreased well-being more likely. Similar to the resource depletion aspect of COR theory and the ER model, ART, which is rooted in environmental psychology, proposes that work tasks result in a diminished ability to sustain directed attention (Kaplan \& Kaplan, 1989), which is itself a psychological resource, and that a diminished ability to sustain directed attention may lead to irritability and stress (Kaplan, 1995). 
While COR theory (Hobfoll, 1989), the ER model (Meijman \& Mulder, 1998), and ART (Kaplan \& Kaplan, 1989) all suggest a link between psychological resource depletion and poor well-being, work grounded in each theoretical perspective also provides guidance on replenishment or restoration in some form, albeit through different mechanisms, which is particularly relevant here. Notably, work in COR theory and the ER model has focused on respite as a means of resource replenishment and recovery, respectively (Etzion, Eden, \& Lapidot, 1998; Flaxman et al., 2012; Fritz \& Sonnentag, 2006; ten Brummelhuis \& Bakker, 2012; Winwood, Bakker, \& Winefield, 2007). Respite from work may include evenings and weekends (ten Brummelhuis \& Bakker, 2012), vacations (Fritz \& Sonnentag, 2006), workday breaks (Hunter \& Wu, 2016), sabbaticals (Davidson et al., 2010) or even engagement in other demanding activities such as military reserve service (Etzion, Eden, \& Lapidot, 1998).

Not all respites are equally effective. In the ER model, the recovery effects of respite depend on psychological detachment from work, mastery experiences, relaxation, and control (Etzion, Eden, \& Lapidot, 1998; Sonnentag, Binnewies, \& Mojza, 2008; Sonnentag et al., 2014; ten Brummelhuis \& Bakker, 2012). DeArmond, Matthews, and Bunk (2014) found that workload was negatively associated with psychological detachment from work, which in turn led to a breakdown in self-regulatory behavior, specifically procrastination, through increased fatigue. Similarly, Sonnentag et al. (2014) found that exhaustion makes it more difficult to psychologically detach from work, which prevents sufficient resource recovery, a relationship which is strengthened by time pressure but, encouragingly, weakened by engagement in leisure activities. Thus, increasing workloads and the resulting exhaustion faced by faculty are not only depleting psychological resources; they may also be preventing adequate resource replenishment and recovery, leading to a negative spiral and increased difficulty of recovery. These 
perspectives suggest that this breakdown in resource replenishment and recovery is contributing to poor mental health and well-being among faculty; however, they also offer guidance on countering these effects through their pluralistic conceptualizations of what can constitute respite or restorative activities.

Similar to the resource depletion aspect of COR theory and the ER model, ART proposes that work tasks result in a diminished ability to sustain directed attention but differs from COR theory and the ER model in its focus on the elements of certain environmental spaces that facilitate attention restoration (Berto, 2014; Kaplan, 1995; Kaplan \& Kaplan, 1989). ART was born in part to explain the role of natural environments in restoration (Kaplan, 1993; Kaplan, 1995; Kaplan \& Kaplan, 1989). Specifically, ART posits that spaces that require being away, evoke fascination, sufficiently engage the mind, and are compatible with the individual in the space can restore the ability for directed attention and effort depleted through engaging in work (Kaplan, 1995; Kaplan \& Kaplan, 1989). This focus on not only the space but on the individual in the space through the compatibility and extent elements suggests then that attention restoration, and the accompanying positive mental health effects, requires individually tailored restorative spaces; spaces that facilitate restoration for some may not facilitate restoration for others if those spaces are not equally compatible with the individuals in focus. We see this focus on the role of the environment and the specific person in it on restoration not as competing with the lessons on respite found in the COR and ER literatures, which are not focused on aspects of environment, but as complementing. Thus, each theoretical perspective adds value to our work here, as we are concerned with not just certain spaces but also how we engage in different activities in them as we seek to address poor mental health and well-being among faculty through replenishment and restoration. 


\section{Bringing Restoration to the Foreground}

The COR, ER, and ART lenses provide insights for restoring psychological resources, thus improving mental health and well-being. However, taboos around mental health and wellbeing within the academy (Thomas, 2014) may prevent faculty from fully incorporating these insights to improve their own well-being, reflecting what Smith and Ulus (2019: 12) state is "an endemic culture of shame around our wellness." Their work, which sheds light on the poor emotional well-being of many within the academy through sharing disclosures of those individuals' experiences, calls for openness to discussions of well-being. Referring to the negative effects on mental health from work intensification, competition, peer review, and other elements of academic life, they state, "Addressing the violence of academia requires discussing directly these embodied experiences, changing Higher Education institutional structures, reflecting on our relational capacities and organizing solidarity at work, with love" (Smith \& Ulus, 2019:12). In light of this call, we provide six unique narratives of academics using spaces for restoration and improved well-being. These narratives follow Jones's $(2014,2018)$ work on the power of counter-spacing for challenging organizational pressures and answer his hope that we identify our own restorative counter-spacing opportunities. Moreover, this socio-spatial notion of encouraging restorative spacing in others offers a potential collective agency to embody a positive spiral of hope for more systemic change, rather than a continued negative spiral of depletion and degeneration. Vesala and Tuomivaara (2018:1390) recently called for

more research around how a place (or spac(e)ing in this case) "can support community-building and restore a healthy work rhythm.”

These narratives, and this project more broadly, resulted from discussions at the 2019 Research in Management Learning and Education (RMLE) UnConference held in Dubrovnik, 
Croatia (see Friedman et al., 2020). For this UnConference, contributors submitted questions, ideas, and concerns, which the conference organizers used to form initial discussion groups around common themes. Periods of discussion over two days were punctuated by short presentations to the other UnConference participants, and discussion groups evolved in membership as participants found topics of interest in other groups. Early in those discussions, we discovered a shared exhaustion around either elements of academic life or sheer work overload. We began to discuss the roots of that exhaustion and how each of us worked to overcome it, when one author explained his restorative space. This prompted each of us to reflect on the role of spaces for restoration and replenishment and whether we, too, had such spaces. We found that sharing with each other about our own spaces for restoration was in itself cathartic, and we began to explore why. Following the conference, each participant in that discussion group developed the restorative space narratives that follow. We hope that by sharing these experiences, we demonstrate that restorative spaces are not one size fits all, and that there need not be shame in making use of them in academic life. Moreover, we seek to "organize solidarity," that is, to build community not just around disclosure of poor mental health and wellbeing (Smith \& Ulus, 2019), but also around recovery and restoration.

\section{A Rural Retreat (Author 4).}

A distant cock crows. Half asleep, I try to work out where I am.

My head is full of noises, different noises: city noises; work noises; voices of needy students, complaining students, and sometimes excited and challenging students; voices of competitive colleagues, critical colleagues, and stimulating colleagues; administrative voices; and reviewer voices. Demanding and persistent voices that can and must be answered and which, in so doing, bring a sense of achievement and vocation but also drain and dishearten. I often feel 
overwhelmed by these competing voices and feel the need to withdraw and to turn down their volume. I put my out-of-office on, "I am away doing research." This is code. I am privileged to have a rural retreat to go to when the noise feels too much, and when I don't need to be in the city. For me both regular and emergency retreating is an essential part of my own self-care and restoration.

The country is not quiet, from the dawn cock to morning egg laying to the evening swifts and night cicadas, these noises are not directed at me, and I can't understand the messages they contain. In my retreat, I stop instinctively blocking out noise. Instead, I try to listen-I walk at dawn, I garden, I watch the sunset, I sit on the terrace and gaze at the stars, each phase of the day brings its own unique noise set.

The noises help me to establish different routines: country routines, retreat routines. Instead of jumping out of bed and booting up my laptop, I sit on the doorstep and listen to the cacophony of the dawn. I leave the house and walk through deserted streets and fields listening to my own footsteps on the damp ground. I listen to the rain dripping through the trees and to the gentle wind of the south, to the competitive cocks and the assorted cooings of doves and wood pigeons. I listen to the start of daily routines: shutters opening, coffee being made, the tractor starting up. My working day is punctuated by acts of conscious listening to the environment I'm in, rather than noises from the environment I am retreating from.

Singing in Community (Author 3). The conductor lifts the baton, the room is still, a collective intake of breath, and then an explosion of sound permeates the room. At choral rehearsals, making music as part of a community, we value the composer's craft and interpret notes on a page with imagination, applying dynamic nuances that lend meaning in a context that exists sometimes centuries beyond the music's creation. Here, uninvited invasions on my 
creativity dissipate fully into thin air, and I am transported to a space of serene and yet intellectually stimulating activity that is, uncharacteristically, just for me. It is a sacred space and time for me, one I consider inviolate.

The discipline of singing is intense. We read the music, attaching words to the notes with syllables not always falling as they normally would in our mouths, in languages that we had never previously learned, and in rhythms and tempos that are unexpected and change swiftly. The eye is moving constantly across the page and darting up to catch the conductor's baton and beat. All of this is accomplished in the company of dozens of other singers, equally focused and resolute, many of whom are strangers, united in a purposeful goal. We cooperate with each other wordlessly - it is completely organic. The intensity of the task does not diminish the restorative nature of the experience, which is largely attributable to the way the mind works to alter the corporal and emotional milieu when we sing. The activity is simultaneously calming and energizing. We are touched by music, of course. And we are also healed by its humanity. But ultimately, we enjoy a strong connection between the music we create while singing, the positioning of our voices, the placement of our breathing, and the functioning of our brains. This ritual of singing every week relieves the strain of constant demands associated with my profession and my tendency to over-work.

There is no judgement in this space. Egos are left at the door. Long ago I relinquished the urge to compare my voice to others' in the group to find myself wanting. I am the least selfcritical in this space than in any other I inhabit, and that is incredibly freeing. It takes my breath away to ponder that.

I arrive to rehearsals with my energy wilting from the rigors of the day, and I am transformed to a state of vitality three hours later. Returning to my office the next day, I am able 
to greet my professional tasks with more optimism, with a renewed sense of purpose, and withdare I say-even more joy.

Slow Swimming (Author 2). I am writing this vignette following what I would consider as my own restorative time and space: slow swimming. Looking out to sea, I have sand on my feet, wet hair, bright eyes, and great company—some academic colleagues sharing my slow swim. Slow swimming is a type of swimming I do regularly throughout the week, based on a slow pace, rhythm, and technique of swimming, which endeavors to appreciate the way the swimming stroke connects with your whole body and the relationship with the water and people swimming with you. In many ways, this contrasts with the fast, individual, and competitive pace of academic work I am part of. Pertinently, this fast pace seemed to diminish the effectiveness of my own contributions and the academics I worked with.

Slow swimming represents an attempt to embed a restorative space into my daily routine. Prior to this activity, my restorative spaces were always stored up for weekends or holidays and did not ever compensate for the way I felt on a daily basis in my working life. I was holding my breath until I suddenly could take an almighty quick gulp of air. In contrast, slow swimming gave me a space to breathe, steadily and routinely.

I have been doing this for over ten years both individually and within a group I set up, called the slow swimming club, consisting of multi-disciplinary academics (grown over 10 years to a current total of 20 people), drawn from different levels and universities. This has increasingly taken place within coastal locations, where we all swim together and then meet up in a local cafe to discuss different academic collaborations. Swimming in the sea offers such a special environment, as it provides a dynamic and limitless natural environment, necessitating spontaneity combined with the focus of keeping a steady slow stroke. 
We have often discussed why this common restorative space is so different to other leisure and work activities. In contrast to the constraining tick-box mentality and disembodied, instrumental nature of much of our university work, slow swimming has enhanced our sensual and temporal sensibilities within a non-competitive, immersive, and collegiate activity.

Restorative Rounds (Author 1). I live in the golf capital of the U.S. But I moved here for a job, and the pressures of the tenure track left no time for such pursuits as the game of golf. When I had extra time, I spent it travelling, socializing, or reading. But while leading a group of students to the U.K. in 2017, I found myself on the Old Course in St. Andrews. I was not ignorant of the gravity of the place for golfers - and if I had been, that ignorance would have been quickly remedied by even a casual observation of the players. This was a sacred place for them. Somewhat perplexed, I made a mental note to see what this seemingly spiritual pursuit was all about when I returned home and went on my way toward the cathedral ruins, where I wandered unaware of the importance to golf of a few of those interred there.

When I returned home, I told a couple of colleagues that I wanted to learn to play golf. Our college houses a golf management program, and the campus includes a golf course. A kind colleague offered to get me started with a few lessons. Golf looked easy on TV, so I figured a few lessons would set me well on my way to proficiency. By the end of the first lesson, I was hooked. I was terrible, but I was hooked. Before long I was playing every chance I could get. The pressures of the fall semester stymied my progress, but I continued to play, usually only nine holes once or twice a week. My game only marginally improved. Interestingly, despite the slow progress, I always felt better after playing than I did before. I soon came to love it not just for the greatness of the game but for its restorative nature. I understand now why many golfers view not only St. Andrews but each round as sacred. 
Playing golf allows you to shut out the noise of the world. Each shot is an exercise in concentration. There is no room for email or faculty meetings; the game is challenging enough to require your full attention. And you are surrounded by nature's beauty and man's attempts to improve it, reflecting well on both the Creator and created. If you have never looked out over a course at sunrise to see the fog roll across the hazards or glanced down an impossibly green fairway toward the putting surface in the low pink light of the sunset, then perhaps this seems farfetched. But having played rounds now either catching that sunrise tee time before heading into the office or seeing the sunset from, hopefully, the fairway after a rather stressful day, take my word: this is sacred space and these rounds are restorative.

A Marking Holiday (Author 6). It is the end of term, and my module marking has arrived; present yet absent, it is secreted away and concatenated in virtual boxes. This time, I decide to preserve my well-being and alleviate the stresses through taking a "marking holiday." The aim is to restore the academic sinews while on the job that become blighted in the process of marking 200 assignments in a few weeks.

Before leaving, I had conversations with colleagues and was reticent to punctuate the cathartic exchanges of marking war stories with news of my trip. I chose to keep it private, thus postponing any guilt. Sporting a tan on my return and an overly positive disposition would necessitate some explaining, as it would be incongruent to my usual stress ridden, pasty faced display, born from the sufferance of marking and the nauseating immersion within hundreds of online documents.

I landed in Spain and took the bus into the mountains of Andalusia to find my dual place of work and restoration. I arranged my days to sequence the recursive interplay of marking and rest, with morning exertions and late afternoon restorative time. 
The sun was my captivating regulator, the factory clock, appearing over me at all time and signaling with an arc in the sky how many scripts should have been adjudged against corresponding shadows cast. Regulatory alignment with the rhythms of nature, and the beautiful predictability and settlement of the Spanish sun, was far from the materially bound university, crowded city life, or the cloud ridden U.K. I found the stress of marking was placated by the healing of the restorative space that acted as a counterpoint of well-being.

The difficulties of marking for me include self-discipline, the regulation of work patterns, and thwarting of procrastination. The marking retreat helped me overcome these challenges through a daily interplay of work and the restorative, sunlit rewards of rest for achievement of marking goals. Furthermore, by going away, there was a refusal to change the pleasant habitual practices of the home into a dark satanic marking mill. In the end, being in the alternate restorative space simply helped me in the doing of marking, and on my return, move on to happier pursuits at work, and indeed, home.

The Sabbath (Author 5). My restorative space, or actually time, is the Sabbath ("Shabbat" in Hebrew). In Jewish tradition, Shabbat is a weekly "day of rest" commemorating God's resting on the seventh day, after six days of creation. According to Jewish tradition, "rest" means the total cessation of "work," defined negatively as 39 types of productive activity and positively as being "soulful/mindful". However, the idea of Shabbat as a restorative time is not necessarily a religious observance nor even a Jewish one. The management writer Marilyn Paul (2017) showed how everyone can create a Sabbath tailored to their own particular needs, interests, or lifestyle.

From Friday sundown until Saturday sundown, I refrain from work I do on the other six days. Shabbat begins with a family ceremony and dinner. I go to synagogue on Saturday 
morning followed by another family meal. I have a whole afternoon just to play, read, do light exercise, meet friends and family, nap, meditate, and eat some more (we are Jewish after all), but always at a relaxed pace with no goals to accomplish. Shabbat is an enriching communal experience - strengthening bonds with family, friends, and co-observers.

In accordance with Jewish tradition, I prepare food in advance so I do not have to cook. I do not do business, errands, or shopping. I avoid travel and walk rather than drive. My computer, cell phone, and TV are turned off — all of which provides a healthy break from technologies that control our lives. These boundaries keep this time and space sacred.

Shabbat has a particular rhythm. On Friday evening there is a feeling of letting golaying down the physical and mental burdens of the workweek. I usually experience exhaustion and go to bed early. The feeling of tiredness usually stays with me on Saturday morning, but also the relief and joy of knowing that I have a whole day just to rest and refresh. As the day goes on, I have the feeling of returning to myself. Saturday afternoon and evening have a bittersweet quality - I start to feel reenergized and ready to get back to work, but also sad about Shabbat ending. I end Shabbat with a traditional ceremony involving blessings over wine to symbolize joy, a candle to symbolize the contrast between light and darkness, and breathing in the scent of sweet spices so as to strengthen myself before returning to rush of the work week.

I am not dogmatic and sometimes make exceptions to these traditions, but no matter what pressures I am facing, they rarely intrude on Shabbat. It provides a haven and way to weekly reconnect with family, friends and myself. In Hebrew we say that we "guard, protect, or preserve" Shabbat — and Shabbat protects us.

\section{Discussion}


Our primary goal in sharing these narratives is to demonstrate that effective restorative spaces are inherently personal and unique and in doing so to encourage readers to reflect on their own options for restorative spaces. We hope that this focus on unique restorative spaces helps to break the cycle of resource depletion leading to poor mental health and well-being. This focus on the necessarily individual nature of restorative spaces is supported by each of the three theoretical perspectives earlier discussed. First, COR theory is built on a definition of resources as nearly anything valued by an individual, whether physical or psychological (Hobfoll, 1989). In their review of the nature of resources in COR theory, Halbesleben et al., (2014: 1335) noted, "The value of resources varies among individuals and is tied to their personal experiences and situations. For example, time with family could be viewed as a valuable resource to one person while it may not be valued by someone else or may even be perceived as a threat to other resources (e.g., one's self-esteem in an abusive relationship).” Thus, efforts to conserve psychological resources or acquire new psychological resources through respite may look very different person to person.

Second, in the ER model, effective recovery may be facilitated by psychological detachment from work, mastery experiences, exercise, control, and relaxation (Fritz \& Sonnentag, 2006; Sonnentag, Binnewies, \& Mojza, 2008; Winwood, Bakker, \& Winefield, 2007). However, each of these is dependent on the individual. For example, the ability to psychological detach from work varies across people and jobs, which implies that the characteristics necessary for an effective respite for recovery are likely to differ across individuals (Fritz \& Sonnentag, 2006). Regarding mastery experiences, Sonnentag, Binnewies, and Mojza (2008) noted that these experiences must not overtax the individual, which depends on that individual's capabilities. 
Third, ART specifically highlights how restorative spaces must depend on the individual in question through the requirements for compatibility and extent (Kaplan \& Kaplan, 1989). In detailing the compatibility between one's purpose and the environment, Kaplan (1995: 173) highlighted how different environments may be restorative for some but not others, "If one's purpose is to be frightened by a horror movie, a snake might be a compatible as well as a fascinating stimulus. Likewise, members of a 'snake-oriented religious sect might find snakes both fascinating and compatible. For a great many humans, of course, a snake would fail the compatibility criterion.” Regarding extent, Kaplan and Kaplan (1989) specify that natural environments must present a whole other world from the person's perspective to be restorative.

These lessons, taken with those discussed earlier, help us to make sense of the uniqueness of each of our narratives, but also point toward themes found across them. The chosen restorative spaces range widely from being embedded within natural environment places, social activities, and religious practices. However, the justification which underpinned this eclectic unfolding of restorative spacing was the importance of how they could disconnect us from the all the cognitive, political, cultural performative pressures, perfections, and precarity of our academic lives — both placed upon us and those placed by ourselves.

Dimensions of difference or similarity include the degree of social isolation, regularity and timing, degree of escape from work, experience with a hobby, and the role of nature, among others. Regarding the degree of social isolation, A Rural Retreat and A Marking Holiday both include social isolation, while The Sabbath and Singing in Community require social integration, one through family connection and the other through shared interests and skills in a community organization. Each of these spaces, however, are similar in that they facilitate psychological 
detachment from work when it is time for work to end, which is in line with the ER model (Sonnentag et al., 2014) and the extent element found in ART (Kaplan \& Kaplan, 1989).

Regarding regularity and timing, Restorative Rounds, Slow Swimming, The Sabbath, and Singing in Community all highlight the need for regular weekly or daily engagement with the restorative space, while A Marking Holiday and A Rural Retreat suggest a more sporadic use of restorative spaces. While these differences may be a function of practicality, they may also highlight differing needs for recovery (van Veldhoven, 2008) or different psychological resource endowments (Halbesleben et al., 2014).

Regarding degree of escape from work, Singing in Community, Restorative Rounds, Slow Swimming, and, especially, The Sabbath highlight restorative spaces that are completely separated from work, while A Marking Holiday and A Rural Retreat are characterized as spaces where both work and rest can be more easily facilitated through the elimination of the regular noises of our academic lives. While these two spaces are in part escapes to work, their physical distancing from the workplace and its accompanying noises allow for more ready escapes from work. That these spaces, too, can lead to restoration is in line with previous work on respite through evenings and weekends away (ten Brummelhuis \& Bakker, 2012), adequate workday breaks (Hunter \& Wu, 2016), and even passing exposure to natural elements (Kaplan, 1993).

Several narratives touch on use of a hobby in a restorative space, but differ on how long such a hobby has been integral to restoration. For example, Singing in Community highlights a longstanding engagement, while Restorative Rounds highlights a nascent fascination. This highlights two lessons from the literature. First, mastery experiences vary by the nature of the task and the individual's abilities (Fritz \& Sonnentag, 2006); thus, the degree to which a hobby facilitates restoration will vary from individual to individual. Second, restorative spaces must be 
compatible with an individual's purpose (Kaplan \& Kaplan, 1989). Purposes to engage in a specific space may change over time, requiring new restorative spaces.

Lastly, these narratives may be compared on how important the natural environment is for facilitating restoration. For example, A Rural Retreat speaks to the "cacophony of the dawn" and of the cicadas, Restorative Rounds mentions the fog at sunrise or the "low pink light of sunset," and Slow Swimming focuses on coastal locations and the water. This is not surprising given that ART was born in large part to explain why some natural environments could restore directed attention (Kaplan \& Kaplan, 1989). But what may be surprising is that similar restorative effects were found in Singing in Community and The Sabbath, which make no mention of the natural environment. This speaks to our earlier contention that each of the theoretical perspectives drawn on here offer complementing rather than competing and mutually exclusive perspectives on what may constitute a restorative space.

\section{Recommendations for Individuals}

On the most fundamental personal level, the restorative spaces here remind us of the importance of self-care through re-engaging our bodies and emotions within spaces, times, and places. Thus, our primary recommendation is for individual academics to reflect on how they can or do use certain spaces for restoration. For those without a restorative space, our narratives and theorizing around them provide some guidance for creating one. Recognize that your restorative space is inherently personal. As we discuss, our narratives show the individuality of each space, and while you may find that your restorative space resembles one of ours, you are perhaps more likely to find that it does not. Our restorative spaces are as varied as we are and are not likely feasible options for all. For example, the focus on physical distancing in A Rural Retreat and A Marking Holiday may be either cost or time prohibitive, while Restorative Rounds and Singing 
in Community require physical abilities that may discourage some from participating. Again, each theoretical perspective drawn on here supports this idea that our spaces for restoration must be informed by our individuality.

When creating your restorative space, consider elements that will allow you to turn off or tune out the noises of everyday academic life. In the respite literature, this is called psychological detachment from work (Sonnentag et al., 2014), while in ART this is called soft fascination, which is an involuntary or non-directed, absorbed attention in which an individual's attention is effortlessly engaged, intrigued, and captured without mental fatigue (Kaplan \& Kaplan, 1989). These recommendations allow for the creation of restorative spaces as diverse as this journal's audience. Your restorative space may be found in a new or old hobby, exercise routines, social engagement, interactions with nature, family time, escapes to a favorite location, or even civic engagement. You may need your restorative space daily, weekly, or sporadically, and you may need to stay there for hours or days. Beyond a couple of guideposts, no one can tell you exactly what your space for restoration requires.

Additionally, after reflecting on and creating your own restorative spaces, we recommend sharing about your restorative space experiences with colleagues for two reasons. First, it amounts to an effort to counter the busyness narrative and culture of shame around mental health, which is in line with the Smith and Ulus (2019: 12) call for "reflecting on our relational capacities and organizing solidarity at work, with love." Second, our own experiences in the conversations that led to this essay and in writing about our own restorative spaces demonstrate the value of vulnerably sharing about our need for restoration and the spaces we created for it. What we found is that disclosing such intensely personal stories, which required a process of building mutual trust, collective care, and freedom of expression and contestation, allowed us to 
assert our restorative agency by raising the conversation, coming together within all pedagogical, research and citizenship aspects of our academic work, embracing these counter, restorative spacing opportunities (Jones, 2018). Like we experienced in our discussion circle, in sharing your own stories, you may empower those around you to do the same. In our case, that empowerment was the result of discussion in a small group at a conference (Friedman et al., 2020). We leave open the range of what sort of interactions may also facilitate these benefits, from one-on-one conversations to broadcast narratives on social media. This recommendation is in line with Whetten's (2001) called for collegium_ “a fellowship among colleagues” — which requires relationship building within the academy beyond those that are purely instrumental.

\section{Recommendations for Colleges and Universities}

While our work here is focused on discussion of our own restorative spaces in the hopes that individuals will seek out their own and encourage others to do the same, we do see a role for colleges and universities for facilitating restorative spacing, even if indirectly. In the context of the emotional fallout of manuscript rejection, Day (2011) encouraged higher education institutions to recognize scholars' full humanity and choose to care, which is a sentiment we echo. However, given that restorative spaces are inherently individual, we do not recommend that academic organizations attempt to create specific spaces that they deem restorative and then expect faculty to engage in them. Rather, colleges and universities should focus on pulling back the increased workloads (Baker, Pifer, \& Lunsford, 2016; Flaherty, 2018; Krause, 2018; Shaw, 2014) and environment of haste and hurry (Berg \& Seeber, 2016) that are leading to resource depletion, failure to adequately recover, and the associated damage to faculty mental health and well-being. Where this is not possible, colleges and universities must encourage boundary setting between professional and personal lives to provide faculty with the opportunity to create 
restorative spaces outside of work. While doing so will likely positively affect faculty mental health and well-being, which is our primary consideration, it will also likely lead to improved performance, which is certainly a desired outcome for academic organizations, as the resource loss spiral associated with a failure to adequately replenish or recover can have negative effects on performance outcomes (Pang, 2016; ten Brummelhuis \& Bakker, 2012).

\section{Conclusion}

The changing academic landscape, resulting in increased workloads and speed, and the nature of academic work is taking a toll on faculty mental health and well-being (Baker, Pifer, \& Lunsford, 2016; Flaherty, 2018; Krause, 2018; Shaw, 2014; Smith \& Ulus, 2019). Work overload makes replenishment, recovery, and restoration more difficult, resulting in a negative spiral. In this essay, we have focused on one coping tool for reversing this spiral: restorative spaces. Our restorative spaces are as unique as we are, but the results of spending time in them are similar. We provide guidance for individuals wanting to create their own restorative spaces, but we must go further. When we consider our own sharing about our restorative spaces, what is most evident is that such restorative conversations represent not the end at all, but hopefully a new beginning within academia_ capturing a wider conversation which reconnects us in a more critical and emancipated sense, by listening to what is precious to us, spatially, socially and sacred within and outside our working lives. Our hope is that this restorative turn offers a corporeal and affective pathway to assert our collective agency on a managerialist system, which desperately needs the passionate politics of generosity (Diprose, 2002). 


\section{References}

Baker, V. L. Pifer, M. J., \& Lunsford, L. G. (2016). Faculty challenges across rank in liberal arts colleges: A human resources perspective. Journal of Faculty Development, 30(1), 21-27.

Berg, M., \& Seeber, B. K. (2016). The Slow Professor: Challenging the Culture of Speed in the Academy. Toronto, Canada: University of Toronto Press.

Berto, R. (2014). The role of nature in coping with psycho-physiological stress: A literature review on restorativeness. Behavioral Sciences, 4(4), 394-409.

Bristow, A., Robinson, S., \& Ratle, O. (2019). Academic arrhythmia: Disruption, dissonance, and conflict in the early-career rhythms of CMS academics. Academic of Management Learning \& Education, 18(2), 241-260.

Brower, H. H. (2013). From the editors: Professor as calling. Academy of Management Learning \& Education, 12(4), 537-539.

Bunderson, J. S., \& Thompson, J. A. (2009). The call of the wild: Zookeepers, callings, and the double-edged sword of deeply meaningful work. Administrative Science Quarterly, 54, $32-57$.

Carnevale, A. T., Gainer, L. J., \& Meltzer, A. S. (1990). Workplace basics: The essential skills employers want. San Francisco: Jossey-Bass.

Chanler, M. (2019). 2019 global talent trends: the four trends transforming your workplace. Report, LinkedIn Talent Solutions, US.

Craig, R., Amernic, J., \& Tourish, D. (2014). Perverse audit culture and accountability of the modern public university. Financial Accountability \& Management, 30(1), 1-24.

Davidson, O. B., Westman, M., Cohen-Charash, Y., Hammer, L. B., Kluger, A. N., Krausz, M., Maslach, C., O’Driscoll, M., Perrewe, P. L., Quick, J. C., Rosenblatt, Z., \& Spector, P. E. 
(2010). Sabbatical leave: Who gains and how much? Journal of Applied Psychology, 95(5), 953-964.

Day, N. E. (2011). The silent majority: Manuscript rejection and its impact on scholars. Academy of Management Learning \& Education, 10(4), 704-718.

DeArmond, S., Matthews, R. A., \& Bunk, J. (2014). Workload and procrastination: The roles of psychological detachment and fatigue. International Journal of Stress Management, 21(2), 137-161.

Diprose, R. (2002). Corporeal Generosity: On Giving With Nietzsche, Merleau-Ponty and Levinas. New York, NY: SUNY.

Etzion, D., Eden, D., \& Lapidot, Y. (1998). Relief from job stressors and burnout: Reserve service as a respite. Journal of Applied Psychology, 83(4), 577-585.

Flaherty, C. (2018). Less is more: College and university administrators discuss how to thoughtfully reduce faculty duties, to help them advance their best work. Inside Higher Ed. Retrieved from: https://www.insidehighered.com/news/2018/01/26/college-anduniversity-administrators-discuss-how-thoughtfully-reduce-faculty-duties.

Flaxman, P. E., Bond, F. W., \& Kinman, G. (2012). Academics' experiences of a respite from work: Effects of self-critical perfectionism and perseverative cognition on postrespite well-being. Journal of Applied Psychology, 97(4), 854-865.

Friedman, V., Robinson, S., Egan, M., Jones, D., Rhew, N., \& Sama, L. (2020). Meandering as method for conversational learning and collaborative inquiry. Journal of Management Education. Advance online publication. doi:10.1177/1052562920934151. 
Fritz, C., \& Sonnentag, S. (2006). Recovery, well-being, and performance-related outcomes: The role of workload and vacation experiences. Journal of Applied Psychology, 91(4), 936945.

Gaultney, J. F. (2010). The prevalence of sleep disorders in college students: Impact on academic performance. Journal of American College Health, 59(2), 91-97.

Halbesleben, J. R. B., Neveu, J-P., Paustian-Underdahl, S. C., \& Westman, M. (2014). Getting to the "COR": Understanding the role of resources in conservation of resources theory. Journal of Management, 40(5), 1334-1364.

Harley, B. (2019). Confronting the crisis of confidence in management studies: Why senior scholars need to stop setting a bad example. Academy of Management Learning \& Education, 18(2), 286-297.

Harley, S., Muller-Camen, M., \& Collin, A. (2004). From academic communities to managed organisations: The implications for academic careers in UK and German universities. Journal of Vocational Behavior, 64, 329-345.

Hobfoll, S. E. (1989). Conservation of resources: A new attempt at conceptualizing stress. American Psychologist, 44, 513-524.

Horn, S. A. (2016). The social and psychological costs of peer review: Stress and coping with manuscript rejection. Journal of Management Inquiry, 25(1), 11-26.

Hunter, E. M., \& Wu, C. (2016). Give me a better break: Choosing workday break activities to maximize resource recovery. Journal of Applied Psychology, 101(2), 302-311.

Jones, D. R. (2014). Restorative counter-spacing for academic sustainability. Organization \& Environment, 27(3), 297-314. 
Jones, D. R. (2018). Could slow be beautiful? Academic counter-spacing within and beyond “The Slow Swimming Club.” Journal of Management Inquiry, 27(4), 430-435.

Kaplan, R. (1993). The role of nature in the context of the workplace. Landscape and Urban Planning, 26, 193-201.

Kaplan, R., \& Kaplan, S. (1989). The Experience of Nature: A Psychological Perspective. Cambridge, UK: Cambridge University Press.

Kaplan, S. (1995). The restorative benefits of nature: Toward an integrative framework. Journal of Environmental Psychology, 15, 169-182.

Kenny, J. (2018). Re-empowering academics in a corporate culture: An exploration of workload and performativity in a university. Higher Education, 75, 365-380.

Kovoor-Misra, S. (2012). Academic decathletes: Insights from the metaphor and an exemplar. Journal of Management Inquiry, 21(3), 279-296.

Kraimer, M. L., Greco, L., Seibert, S. E., \& Sargent, L. D. (2019). An investigation of academic career success: The new tempo of academic life. Academy of Management Learning \& Education, 18(2), 128-152.

Krause, G. (2018). We must confront the culture of overwork to tackle academia's mental health crisis. Times Higher Education. Retrieved from:

https://www.timeshighereducation.com/blog/we-must-confront-culture-overwork-tackleacademias-mental-health-crisis.

Lippman, L., Atienza, A., Rivers, A., et al. (2008). A developmental perspective on college and workplace readiness. Report, Child Trends and the Bill and Melinda Gates Foundation, USA. 
Matthews, V. (2017). Mental health at business school: 'The anxiety was overwhelming.'

Financial Times. Retrieved from: https://www.ft.com/content/e3824c38-81c3-11e7-94e2c5b903247afd.

Meijman, T. F., \& Mulder, G. (1998). Psychological aspects of workload. In P. J. D. Drenth \& H. Thierry (Eds.), Handbook of work and organizational psychology, volume 2: Work psychology (pp. 5-33). Hove, England: Psychology.

Mitchell, T. R. (2007). The academic life: Realistic changes needed for business school students and faculty. Academy of Management Learning \& Education, 6(2), 236-251.

Mudrak, J., Zabrodska, K., Kveton, P., Jelinek, M., Blatny, M., Solcova, I., \& Machovcova, K. (2018). Occupational well-being among university faculty: A job demands-resources model. Research in Higher Education, 59, 325-348.

Pang, A. S. K. (2016). Rest: Why You Get More Done When You Work Less. New York, NY: Basic Books.

Paul, M. (2017). An oasis in time: How a day of rest can save your life. Emmaus, PA: Rodale Books.

Shaw, C. (2014). Overworked and isolated: Work pressure fuels mental illness in academia. The Guardian. Retrieved from: https://www.theguardian.com/higher-educationnetwork/blog/2014/may/08/work-pressure-fuels-academic-mental-illness-guardian-studyhealth

Smith, C., \& Ulus, E. (2019). Who cares for academics? We need to talk about emotional wellbeing including what we avoid and intellectualize through macro-discourses. Organization. Advance online publication. 
Sonnentag, S. (2003). Recovery, work engagement, and proactive behavior: A new look at the interface between nonwork and work. Journal of Applied Psychology, 88(3), 518-528.

Sonnentag, S., Arbeus, H., Mahn, C., \& Fritz, C. (2014). Exhaustion and lack of psychological detachment from work during off-job time: Moderator effects of time pressure and leisure experiences. Journal of Occupational Health Psychology, 19(2), 206-216.

Sonnentag, S., Binnewies, C., \& Mojza, E. (2008). “Did you have a nice evening?” A day-level study on recovery experiences, sleep, and affect. Journal of Applied Psychology, 93, 674684.

Stixrud, W. R. (2012). Why stress is such a big deal. Journal of Management Education, 36(2), $135-142$.

Strati, A. (2007). Sustainable knowledge and practice-based learning. Management Learning, 38, $61-77$.

ten Brummelhuis, L. L., \& Bakker, A. B. (2012). Staying engaged during the week: The effect of off-job activities on next day work engagement. Journal of Occupational Health Psychology, 17(4), 445-455.

Thomas, K. (2014). We don't want anyone to know, say depressed academics. The Guardian. Retrieved from: https://www.theguardian.com/higher-educationnetwork/blog/2014/may/08/academics-mental-health-suffering-silence-guardian-survey van Veldhoven, M. (2008). Need for recovery after work: An overview of construct, measurement, and research. In J. Houdmont \& S. Leka (Eds.), Occupational Health Psychology: European Perspectives on Research, Education, and Practice, Volume 3, (pp. 1-25). Nottingham, England: Nottingham University Press. 
Vesala, H., \& Tuomivaara, S. (2018). Experimenting with work practices in a liminal space: A working period in a rural archipelago. Human Relations, 71(10), 1371-1394.

Walsh, J. P. (2011). Embracing the sacred in our secular scholarly world. Academy of Management Review, 36(2), 215-234.

Whetten, D. A. (2001). What matters most. Academic of Management Review, 26(2), 175-178.

Winwood, P. C., Bakker, A. B., \& Winefield, A. H. (2007). An investigation of the role of nonwork-time behavior in buffering the effects of work strain. Journal of Occupational and Environmental Medicine, 49(8), 862-871. 